University of Nebraska - Lincoln

DigitalCommons@University of Nebraska - Lincoln

\title{
Tracking plant physiological properties from multi-angular tower- based remote sensing
}

Thomas Hilker

University of British Columbia, thomas.hilker@ubc.ca

Anatoly A. Gitelson

University of Nebraska at Lincoln, agitelson2@unl.edu

Nicholas C. Coops

University of British Columbia

Forrest G. Hall

Goddard Space Flight Center

T. Andrew Black

University of British Columbia

Follow this and additional works at: https://digitalcommons.unl.edu/natrespapers

Part of the Natural Resources and Conservation Commons

Hilker, Thomas; Gitelson, Anatoly A.; Coops, Nicholas C.; Hall, Forrest G.; and Black, T. Andrew, "Tracking plant physiological properties from multi-angular tower-based remote sensing" (2011). Papers in Natural Resources. 243.

https://digitalcommons.unl.edu/natrespapers/243

This Article is brought to you for free and open access by the Natural Resources, School of at DigitalCommons@University of Nebraska - Lincoln. It has been accepted for inclusion in Papers in Natural Resources by an authorized administrator of DigitalCommons@University of Nebraska - Lincoln. 


\title{
Tracking plant physiological properties from multi-angular tower-based remote sensing
}

\author{
Thomas Hilker - Anatoly Gitelson - Nicholas C. Coops • \\ Forrest G. Hall $\cdot$ T. Andrew Black
}

Received: 5 August 2010/Accepted: 24 December 2010

(C) Springer-Verlag 2011

\begin{abstract}
Imaging spectroscopy is a powerful technique for monitoring the biochemical constituents of vegetation and is critical for understanding the fluxes of carbon and water between the land surface and the atmosphere. However, spectral observations are subject to the sunobserver geometry and canopy structure which impose confounding effects on spectral estimates of leaf pigments. For instance, the sun-observer geometry influences the spectral brightness measured by the sensor. Likewise, when considering pigment distribution at the stand level scale, the pigment content observed from single view angles may not necessarily be representative of stand-level conditions as some constituents vary as a function of the degree of leaf illumination and are therefore not isotropic. As an alternative to mono-angle observations, multi-angular remote
\end{abstract}

Communicated by Gerardo Avalos.

T. Hilker $(\bowtie) \cdot$ N. C. Coops

Faculty of Forest Resources Management, University of British Columbia, 2424 Main Mall, Vancouver, BC V6T 1Z4, Canada

e-mail: thomas.hilker@ubc.ca

\section{A. Gitelson}

School of Natural Resources, University of Nebraska Lincoln,

303 Hardin Hall, 3310 Holdrege, Lincoln, NE 68583-0973, USA

F. G. Hall

Joint Center for Earth Systems Technology,

University of Maryland, Baltimore County, USA

F. G. Hall

Code 614.4, Goddard Space Flight Center,

Greenbelt, MD 20771, USA

T. A. Black

Faculty of Land and Food Systems, University of British

Columbia, 2357 Main Mall, Vancouver, BC V6T 1Z4, Canada sensing can describe the anisotropy of surface reflectance and yield accurate information on canopy structure. These observations can also be used to describe the bi-directional reflectance distribution which then allows the modeling of reflectance independently of the observation geometry. In this paper, we demonstrate a method for estimating pigment contents of chlorophyll and carotenoids continuously over a year from tower-based, multi-angular spectro-radiometer observations. Estimates of chlorophyll and carotenoid content were derived at two flux-tower sites in western Canada. Pigment contents derived from inversion of a CR model (PROSAIL) compared well to those estimated using a semi-analytical approach $\left(r^{2}=0.90\right.$ and $r^{2}=0.69, P<0.05$ for both sites, respectively). Analysis of the seasonal dynamics indicated that net ecosystem productivity was strongly related to total canopy chlorophyll content at the deciduous site $\left(r^{2}=0.70, P<0.001\right)$, but not at the coniferous site. Similarly, spectral estimates of photosynthetic light-use efficiency showed strong seasonal patterns in the deciduous stand, but not in conifers. We conclude that multi-angular, spectral observations can play a key role in explaining seasonal dynamics of fluxes of carbon and water and provide a valuable addition to fluxtower-based networks.

Keywords Prosail - Chlorophyll - Carotenoid . Phenology $\cdot$ Radiative transfer - Light-use efficiency . AMSPEC

\section{Introduction}

The physiological status of vegetation canopies is governed by their biochemical constituents, such as enzymatic and photosynthetic compounds, carbohydrates and 
light-harvesting complexes, which are associated with chlorophyll, photoprotective and auxiliary pigments (Zhang et al. 2007). Vegetation can mediate up to $90 \%$ of the gas exchange between the terrestrial bio-geosphere and the atmosphere (Damm et al. 2010; Ozanne et al. 2003). As a result, monitoring these constituents will aid in our understanding of carbon and water fluxes between the land surface and the atmosphere and improve our knowledge of the terrestrial energy budget (Field et al. 1992).

Image spectroscopy is a powerful technique for monitoring plant physiological properties and measuring changes in plant pigment contents over time (Bicheron and Leroy 1999). Broadly, remote sensing of leaf and canopy biochemical composition can be classified into empirical, semi-analytical and analytical approaches (Ustin et al. 2009). The former two are largely based on spectral vegetation indices (SVI) which are linear and non-linear combinations of reflectance at discrete spectral bands to maximize sensitivity to canopy characteristics (Hall et al. 1995; Price 1992). Analytical techniques infer biochemical properties from the inversion of canopy reflectance (CR) models, which, based on radiative transfer theory and coupled with leaf optical models, simulate the reflectance and the transmittance of a leaf as a function of its constituents (Meroni et al. 2004). While these models require additional input parameters to determine the radiative transfer through the canopy, they allow the estimation of both leaf and canopy parameters from model inversion, thereby overcoming the need to parameterize empirical models (Bicheron and Leroy 1999; Jacquemoud et al. 2009; Privette et al. 1996).

One of the fundamental challenges in using optical remote sensing for measuring canopy pigment contents is the dependence of these measurements on extraneous effects such as soil background effects and the observation geometry (Kempeneers et al. 2008). For instance, canopy level estimates of biophysical parameters from spectral vegetation indices are strongly affected by the viewing and solar geometry (Myneni et al. 1995; Verstraete et al. 1996), which makes a comparison between measurements taken from different perspectives or during different times of the day or year difficult (Los et al. 2005). Several studies have inverted canopy reflectance models to mitigate these effects (Jacquemoud et al. 2000; Kuusk 1998; Weiss et al. 2000); however, research has shown that differences in the proportion of non-photosynthetic background and canopy structure from such measurements is not always sufficiently accounted for (Zarco-Tejada et al. 2004). For instance, Kempeneers et al. (2008) investigated directional effects on several turbid medium models and found that quantitative chlorophyll measures largely depended on viewing and background conditions for regression and model inversion. Similarly, Verrelst et al. (2008) investigated the directional sensitivity of spectrally determined pigment estimates using multi-angular satellite data and found strong dependencies on background and structural effects for most of the investigated sites. Studies have also shown that pigment content in different parts of the canopy can vary significantly with the degree of illumination and, as a result, the pigment content observed from an individual view angle may not be representative of the entire canopy (Hall et al. 2008; Matsubara et al. 2008).

As an alternative to traditional, mono-angle observations, multi-angular data simultaneously acquired at the same location provide a means to characterize the anisotropy of surface reflectance (Chen et al. 2003), which has been shown to contain information on the structure of vegetated surfaces and shaded parts of the canopy (Chen et al. 2003; Gao and Schaaf 2003). Multi-angular data also allow characterization of the bi-directional reflectance distribution of surface reflectance (Chen and Leblanc 1997; Gao and Schaaf 2003) which facilitates modeling of canopy reflectance independently of the sun-observer geometry. As a result, multi-angular observations can help overcome the limitations faced by traditional remote sensing techniques and yield more robust estimates of canopy constituents. While globally contiguous, multiangular data acquisition is not yet possible, relationships between canopy reflectance and plant physiological processes can be demonstrated at the stand level using permanently established tower-based remote sensing devices (Hilker et al. 2007, 2010b). Knowledge obtained from these types of studies can then be used to develop models for up-scaling reflectance parameters to landscape and global scales.

In this study, we introduce a new approach for continuous measurements of canopy characteristics from multiangular tower-based remote sensing at a coniferous and a deciduous forest stand in western Canada. First, we demonstrate a technique that allows acquisition of canopy reflectance independently of the sun-observer geometry from continuous, multi-angular, tower-based remote sensing. We then demonstrate the robustness of this approach by inferring canopy pigment contents from an analytical and a semi-analytical technique and comparing the results. Finally, the differences in diurnal and seasonal patterns of pigment contents and composition and their impact on vegetation productivity are analyzed and related to biophysical measurements from $\mathrm{CO}_{2}$ exchange. Our study demonstrates that tower-based, multi-angular remote sensing can be a valuable addition to eddy-covariance measurements and can help to relate biochemical composition of plant foliage to biophysical observations of carbon and water fluxes. 


\section{Materials and methods}

Study areas

The coniferous stand (hereafter DF-49) is a 61-year-old second-growth forest located at $300 \mathrm{~m}$ above sea level on Vancouver Island, British Columbia $\left(49^{\circ} 52^{\prime} 7.8^{\prime \prime} \mathrm{N}\right.$, $125^{\circ} 20^{\prime} 6.3^{\prime \prime} \mathrm{W}$ ). It consists of $80 \%$ Douglas fir (Pseudotsuga), $17 \%$ western red cedar (Thuja plicata Donn ex D. Don) and 3\% western hemlock [Tsuga heterophylla (Raf.) Sarg.] (Morgenstern et al. 2004). The stand density is $1,100 \mathrm{stems} \mathrm{ha}^{-1}$, with tree heights ranging between 30 and $35 \mathrm{~m}$ (Chen et al. 2006). The understorey consists mainly of salal (Gaultheria shallon Pursh.), Oregon grape (Berberis nervosa Pursh), vanilla-leaf deer foot [Achlys triphylla (Smith) DC], various ferns and mosses (Morgenstern et al. 2004). The site is located within the dry maritime Coastal Western Hemlock bio-geoclimatic subzone (mean annual temperature $\approx 8.5^{\circ} \mathrm{C}$ ), which is characterized by cool summers and mild winters with occasional drought during late summer (Humphreys et al. 2006).

The mature aspen study site, hereafter Southern Old Aspen (SOA), is located at $53.62889^{\circ} \mathrm{N}, 106.19779^{\circ} \mathrm{W}$ at an altitude of $600 \mathrm{~m}$ in central Saskatchewan. The 86-year old stand is situated in the southern ecotone of the western boreal forest (mean annual temperature $\approx 0.5^{\circ} \mathrm{C}$ ) and consists of trembling aspen (Populus tremuloides) with about $10 \%$ of balsam poplar (Populus balsamifera L.) and a thick, 2-3 m hazelnut understory (Corylus cornuta Marsh) with sparse alder [Alnus crispa (Alt.) Pursch] (Barr et al. 2007). The stem density is about 830 stem$\mathrm{s} \mathrm{ha}^{-1}$ at a mean tree height of about $22 \mathrm{~m}$ (Barr et al. 2007). The site was originally established as part of the BOREAS study carried out between 1994 and 1996 (Sellers et al. 1995).

\section{Spectral observations}

Canopy spectra were obtained from AMSPEC II (Hilker et al. 2010b) (Fig. 1). The automated, tower-mounted system features a pan-tilt unit that allows the sensor head to be moved at any zenith angle $\left(\theta_{\mathrm{v}}\right)$ between $43^{\circ}$ and $78^{\circ}$ and view azimuth $\left(\varphi_{\mathrm{v}}\right)$ between $0^{\circ}$ and $360^{\circ}$. To allow sampling under varying sky conditions, canopy spectra were obtained from simultaneous measurements of solar irradiance and radiance, sampled every $5 \mathrm{~s}$ from sunrise to sunset at a $10^{\circ}$ angular step width (horizontally and vertically), thereby completing a full rotation every $15 \mathrm{~min}$. The spectro-radiometer used is a Unispec-DC (PP Systems, Amesbury, MA, USA) featuring 256 contiguous bands with a nominal band spacing of $3 \mathrm{~nm}$ (full width halfmaximum $10 \mathrm{~nm}$ ) and a nominal range of operation between 350 and 1,200 $\mathrm{nm}$. The upward pointing probe is equipped with a cosine receptor (PP-Systems) to correct sky irradiance measurements for varying solar altitudes.

Two identical units were built and installed at DF-49 and SOA, respectively. AMSPEC II observations at DF-49 were sampled between 14 May and 20 October 2009 and, using a prototype instrument operating at a fixed zenith angle of $\theta_{\mathrm{v}}=63^{\circ}$, between 1 April 2006 and 31 March 2007, and 17 March to 21 October 2008 (Hilker et al. 2007). The SOA system was installed on 26 May 2009 and data were sampled through 4 November 2009. Further details can be found in Hilker et al. (2010a).

One of the improvements implemented in AMSPEC II is a webcam system that is installed in parallel to the downward-pointing probe and automatically samples an image with every spectrum that is observed by the radiometer (Fig. 1). This system was used to demonstrate the plant phenological changes over the year by quantifying the divergence of the red and the blue channel from the brightness observed in the green channel of the camera (Richardson et al. 2007):

$2 G_{-} R B_{i}=2 \mu_{G}-\left(\mu_{R}+\mu_{B}\right)$

where $\mu_{\mathrm{G}}, \mu_{\mathrm{R}}$ and $\mu_{\mathrm{B}}$ are the camera observed brightness values (raw DN) in the green, red and blue channel, respectively. All observations were made at a constant view zenith and view azimuth angle at solar noon (Hilker et al. 2010a).

\section{Eddy flux measurements}

Continuous, half-hourly fluxes of $\mathrm{CO}_{2}$ were acquired at DF-49 and SOA as part of the Canadian Carbon Program.

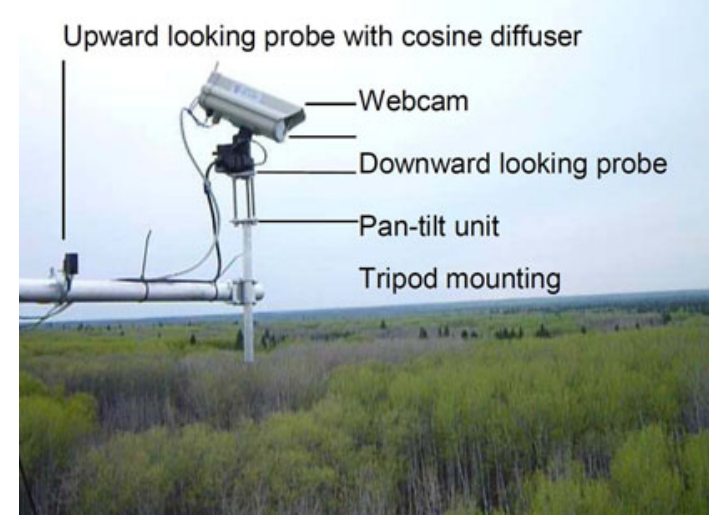

Fig. 1 In-situ photograph of AMSPEC II taken at the Old Aspen site. The system features a pan-tilt unit which allows the sensor head to be moved at any zenith angle between $40^{\circ}$ and $78^{\circ}$ at a view azimuth between $0^{\circ}$ and $360^{\circ}$. The upward-looking sensor features a cosine diffuser to correct for varying solar altitudes. Canopy reflectance is determined from solar irradiance and canopy radiance. A webcam picture is automatically taken with every spectrum that is sampled. An identical system has been installed at the DF-49 site. Figure adapted from Hilker et al. (2010a) 
Net ecosystem exchange (NEE) was determined as the sum of half-hourly fluxes of $\mathrm{CO}_{2}$ and the rate of change in $\mathrm{CO}_{2}$ storage in the air column between ground and EC-measurement level, using a three-axis sonic anemometerthermometer (model R3, both sites; Gill Instruments, Lymington, UK) and a closed-path $\mathrm{CO}_{2} / \mathrm{H}_{2} \mathrm{O}$ infrared gas analyzer (LI-6262, both sites; LI-COR, Lincoln, NE, USA) (Barr et al. 2004; Jassal et al. 2007). Incident and reflected PAR $\left(\mu \mathrm{mol} \mathrm{m} \mathrm{m}^{-2} \mathrm{~s}^{-1}\right.$ ) was measured from upward- and downward-looking quantum sensors (models $190 \mathrm{SZ}$ and 190SA, at DF-49 and SOA, respectively; LI-COR) above and below the canopy and $f_{\mathrm{PAR}}$ was derived at each site from the incident and reflected total PAR measured above and below the canopy.

$f_{\mathrm{PAR}}=\frac{\mathrm{PAR}_{\downarrow, a b v}-\mathrm{PAR}_{\uparrow, a b v}-\mathrm{PAR}_{\downarrow, b l w}}{\mathrm{PAR}_{\downarrow, a b v}}$

where $\mathrm{PAR}_{\uparrow, a b v}$ and $\mathrm{PAR}_{\downarrow, a b v}$ are the up- and down-welling PAR above the canopy, respectively and $\mathrm{PAR}_{\downarrow}, b l w$ is the transmitted PAR measured below the canopy. Gross primary production (GPP) was determined as the difference between NEE and daytime ecosystem respiration $\left(R_{\mathrm{D}}\right)$ (Humphreys et al. 2006) and $\varepsilon$ was calculated as (Monteith 1972, 1977):

$\varepsilon=\frac{\mathrm{GPP}}{\mathrm{PAR} \times f_{\mathrm{PAR}}}$

A complete description of the eddy covariance measurements is given elsewhere (Humphreys et al. 2006; Jassal et al. 2007).

Inversion of the PROSAIL canopy model

Among the most frequently used reflectance models linking leaf and canopy optical properties to biochemical characteristics are PROSPECT (leaf level) and scattering by arbitrary inclined leaves (SAIL) (canopy level) (Jacquemoud et al. 2009). In PROSPECT, leaves are represented as multiple isotropic scatterers based on surface roughness and biochemical leaf composition (Goel and Strebel 1983; Goel and Thompson 1984). SAIL is an extension of a 1-D, "big-leaf" model (Suits 1972) which simulates the bidirectional reflectance factor of turbid medium plant canopies (Jacquemoud et al. 2009; Verhoef 1984). Since leaf reflectance, leaf transmittance, and soil reflectance are three wavelength-dependent input variables of SAIL, the inversion of SAIL to retrieve biophysical variables from canopy reflectance at any given solar and viewing angle in a defined relative azimuthal plane requires at least three times as many variables as wavelengths (Verstraete and Pinty 2001). As a result, the inversion of SAIL is generally impracticable unless several viewing angles are available (Jacquemoud et al. 2009). To reduce the dimensionality of the inverse problem and to assess the canopy biochemistry, SAIL was coupled with PROSPECT to derive PROSAIL (Baret et al. 1992). The inversion of PROSAIL allows the prediction of both leaf and canopy parameters (Bicheron and Leroy 1999; Jacquemoud et al. 2009; Privette et al. 1996). Mathematically, the inversion of PROSAIL is a non-linear minimization problem that can be solved through iterative adjustment of estimated a priori inputs (Verstraete et al. 1996). Different optimization algorithms are available, based on cost functions to minimize the residuals between forward modeled and measured observations (here canopy reflectance). In this study, we selected a trust-region-reflective algorithm based on the interior-reflective Newton method (Coleman and Li 1996; Coleman et al. 2002). The search range of variables used for parameterizing PROSAIL at both sites is given in Table 1.

While hyperspectral input data provide potentially rich information for the estimation of canopy parameters, the use of a subset of bands in the inversion process is recommended, as highly correlated bands will generate artificially weighted results and those bands with higher model and measurement uncertainties would bias the retrieval (Meroni et al. 2004). To reduce this bias, the 15 most significant wavebands out of the 256 input bands provided by AMSPEC were selected using regression tree analysis. To select these bands, PROSAIL was first run in forward mode using all possible combinations of biophysical parameters (step width $1 \%$ of the search range from min to max value; Table 1) to simulate reflectance spectra. Then, a regression tree model was developed to explain the

Table 1 Search ranges for PROSAIL parameters

\begin{tabular}{llllr}
\hline Variable & Description & Unit & Search range & Reference \\
\hline$C_{\mathrm{A}+\mathrm{B}}$ & Chlorophyll A + B content & $\mu \mathrm{g} \mathrm{cm}^{-2}$ & $0-200$ & Meroni et al. (2004), \\
$C$ ar & Carotenoid content & $\mu \mathrm{g} \mathrm{cm}^{-2}$ & $0-200$ & Zhang et al. (2006, 2008, 2009) \\
$C_{\text {brown }}$ & Brown leaf pigments & $\mu \mathrm{g} \mathrm{cm}^{-2}$ & $0-1$ & $0.002-0.08$ \\
$C_{\mathrm{w}}$ & Leaf equivalent water thickness & $\mathrm{cm}$ & $0.002-0.03$ & Chen et al. (2006) \\
$C_{\mathrm{m}}$ & Leaf dry matter content & $\mathrm{g} \mathrm{cm}^{-2}$ & $4-8(\mathrm{DF}-49), 0-4$ (SOA) & \\
LAI & Leaf area index & $\mathrm{m} \mathrm{m}^{2} \mathrm{~m}^{-2}$ & & \\
\hline
\end{tabular}


variability of the model inputs as a function of the modeled reflectance. Wavebands were ranked according to their explanatory power assigned by the regression tree model and the 15 most important wavebands were selected as input observations.

The multi-angular observations obtained from AMSPEC could be used to parameterize PROSAIL directly; however, individual stand-level measurements taken under different view angles and from different portions of the canopy are not necessarily representative of stand-level conditions as they observe varying proportions of non-photosynthetic background. A better praxis to infer stand-level data from AMSPEC is to model the bidirectional reflectance distribution function (BRDF) from multi-angular observations observed in all directions around the tower during short time intervals for which canopy level pigment content is approximately constant (Hilker et al. 2008). One BRDF model can then be established for each time interval and stand level reflectance can be inferred for any sun-observer geometry based on all observations taken during this period. Since PROSAIL predicts the status of the carotenoid pool in general but not specifically changes in the xanthophyll pigment status, which would be subject to more rapid changes (Gamon et al. 1992, 1993; Hall et al. 2008), we selected daily time steps to predict contents of chlorophyll and carotenoids in leaves.

Several approaches exist to modeling the BRDF. One common method is the semi-empirical kernel representation (Roujean et al. 1992; Wanner et al. 1995) which models bidirectional reflectance distribution as linear combination of a number of basic BRDF shapes based on the sun-observer geometry and the surface reflectance (Roujean et al. 1992). Their simple character allows the parameterization from mathematical inversion of multi-angular spectral observations. Different kernel types are available depending on the type of vegetation; the most commonly used kernels for temperate forests are the Ross-Thick-Li-Sparse kernels based on radiative transfer theory (Ross 1981) and a geometric-optical model (Li and Strahler 1985).

Use of vegetation indices for estimation of stand level pigment contents

Chlorophyll and carotenoid contents derived from PROSAIL were compared to estimates from a semi-analytical approach (Gitelson et al. 2003, 2006). Chlorophyll contents were determined from the chlorophyll indices (CI) using reflectance in the green and the NIR ranges (Gitelson et al. 1999, 2003):

$\mathrm{CI}_{\text {green }}=\left(R_{\mathrm{NIR}} / R_{\text {green }}\right)-1$

where $R_{\text {green }}$ is the reflectance in a $30 \mathrm{~nm}$ band centered at $550 \mathrm{~nm}$, and $R_{N I R}$ is the reflectance in a $40 \mathrm{~nm}$ band centered at $780 \mathrm{~nm}$. The corresponding bandwidths were synthesized from AMSPEC observations by averaging the respective channels of the radiometer. Similarly, the carotenoid contents were determined from the carotenoid reflectance index (CRI) using three wavebands (Gitelson et al. 2006)

$\mathrm{CRI}_{\text {green }} \propto\left[R_{510-52}^{-1}-R_{560-570}^{-1}\right] \times R_{\mathrm{NIR}}$

where $R_{510-520}$ and $R_{690-710}$ are reflectances in the bluegreen and the red spectral regions and $R_{\mathrm{NIR}}$ is the reflectance in a $40 \mathrm{~nm}$ band centered at $780 \mathrm{~nm}$.

Finally, the status of the xanthophyll cycle pigments was determined using multi-angular observations of the photochemical reflectance index (PRI) (Gamon et al. 1992, 1993; Hilker et al. 2008)

PRI $=\frac{\rho_{531}-\rho_{570}}{\rho_{531}+\rho_{570}}$

where $\rho_{531}$ and $\rho_{570}$ is the narrow waveband reflectance at 531 and $570 \mathrm{~nm}$, respectively. Methods of Hilker et al. (2008) were used to extract the xanthophyll related signal from multi-angular PRI observations. A complete description of the methods can be found in Hall et al. (2008) and Hilker et al. (2008). Similarly to the PROSAIL estimated canopy characteristics, input reflectance for the spectral vegetation indices was obtained from the BRDF modeled AMSPEC data averaged to daily time steps. In the case of PRI which is related to short-term responses in canopy light-use efficiency (Gamon et al. 1992; Hall et al. 2008), BRDF models were obtained using half-hourly spectral observations and daily PRI values were averaged from these half-hourly BRDF models.

\section{Results}

Seasonal dynamics in leaf pigment contents

Figure 2 shows daily estimates of vegetation phenology observed by AMSPEC's webcam system during the 2009 study period. The seasonal dynamics were much stronger at the Old Aspen site (Fig. 2a) than at the DF-49 site, where almost no changes in canopy greenness were observed. At the SOA site, the minimum of the camera measured $2 G_{-} R_{B}$ was observed at around DOY 175 . Up to then, the camera data showed a decreasing trend. After DOY 175, the webcam observed a substantial green-up of the canopy, which peaked at around DOY 260 (Hilker et al. 2010b). At the DF-49 site, no significant changes in camera-observed greenness were found.

Table 2 shows the 15 most significant wavebands of AMSPEC as derived from regression tree analysis. Pigment content was mainly derived from green wavebands, but 
Fig. 2 Demonstration of the differences in canopy phenology observed from AMSPEC's webcam using methods of Richardson et al. (2007). a Spring green-up and leaf down at SOA is shown in (a) DF-49 is given in (b). One constant view angle was selected to minimize directional effects $\left(\theta_{\mathrm{v}}=73^{\circ}, \varphi_{\mathrm{v}}=65^{\circ}\right)$. The missing data are due to a downtime of AMSPEC at DF49 between DOY 197 and 231. Results adapted from Hilker et al. (2010a)

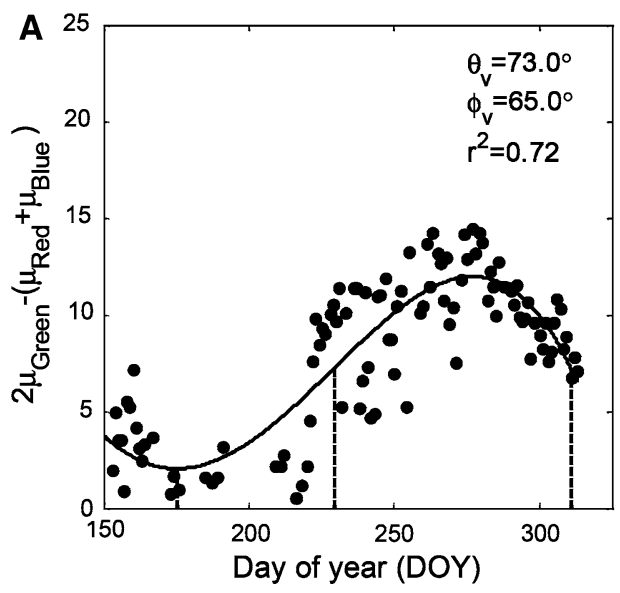

Table 2 Most significant wavebands identified from regression tree analysis

\begin{tabular}{ll}
\hline Region & Selected wavebands $(\mathrm{nm})$ \\
\hline Blue & 400.9 \\
Green & $516.3-522.8,529.4,536$ \\
Lower red edge & $679.9-689.7,699.4$ \\
Upper red edge & $751.4,787.1,809.7,887.2$ \\
\hline
\end{tabular}

also from the lower and upper "red edge" region. Figures $3 \mathrm{a}$ and $\mathrm{b}$ demonstrate the seasonal variation in chlorophyll content as estimated from AMSPEC-derived inversions of PROSAIL and from Eqn. 3 at SOA (a) and DF-49 (b). The pigment content was generally higher at the more productive DF-49 site than at SOA. Both sites showed a seasonal trend, which was, however, much more distinct in the case of the deciduous boreal stand than for the temperate coniferous forest. In both cases, the chlorophyll content of the leaves increased early during the vegetation period (around DOY 150) and peaked at around DOY 230. At both sites, there was a highly significant relationship between PROSAIL-derived pigment estimates and the ones determined using $\mathrm{CI}_{\text {green }}\left[r^{2}=0.90\right.$ for the SOA site (a) and $r^{2}=0.69$ for the DF-49 site (b); $P<0.01$ in both cases].

Figure $4 \mathrm{a}$ and $\mathrm{b}$ show the seasonal dynamics of the carotenoid pigments for SOA (a) and DF-49 (b). The carotenoid content at SOA increased sharply at the beginning of the vegetation period and peaked at around DOY 200. In case of the evergreen stand, carotenoid content was highest during the winter and decreased until about DOY 180. The PROSAIL derived method corresponded well with the semi-analytical approach given in Eqn 4. The coefficient of determination between the canopy reflectance model and CRI green was $r^{2}=0.91$ at the SOA site and $r^{2}=0.66$ at the DF-49 site $(P<0.01)$.
The seasonal dynamics in car/chl is given in Fig. 5 (data shown in Figs. 3 and 4). At SOA, the ratio of carotenoids to chlorophyll was high during the first few weeks of the growing season, after that the chlorophyll content increased much more rapidly and the car/chl ratio was two-fold lower than at the beginning of the season. The ratio remained relatively stable during the summer months and increased again towards the end of the season. A strong seasonal trend in car/chl was also observed at DF-49 (Fig. 5b); however, the relative chlorophyll content (compared to carotenoids) was generally much higher compared to the SOA site, reaching a ratio of chlorophylls to carotenoids of about 3:1 during the peak of the growing season. The index-based method (Eqns. 4 and 5) yielded results similar to the inverted PROSAIL model at SOA $\left(r^{2}=0.52 ; P<0.01\right)$; however, only a weak relationship between the semi-analytical and the analytical approach was found for the DF-49 site $\left(r^{2}=0.10 ; P<0.01\right)$.

The most notable differences were observed in the seasonal dynamics of the status of PRI (Fig. 6). The graphs illustrate daily averages of PRI measured by AMSPEC and photosynthetic light-use efficiency (ع) measured by the eddy covariance system installed at both towers. The SOA site (Fig. 6a) showed a clear seasonal trend in daily estimates of $\varepsilon$, which ranged between daily averages of $0.1 \mathrm{~g} \mathrm{CMJ}^{-1}$ at the beginning and the end of the growing season and $1.6 \mathrm{~g} \mathrm{CMJ}^{-1}$ during early summer. The temporal pattern of LUE and PRI followed seasonal variation of chlorophyll content (Fig. 3a). No seasonal patterns were observed for $\varepsilon$ and PRI at the DF49 site with values ranging between 0.2 and $1.9 \mathrm{~g} \mathrm{CMJ}^{-1}$. In both cases, there was a strong, non-linear relationship between PRI and eddy-flux measured $\varepsilon\left(r^{2}=0.91\right.$, $P<0.01$ for SOA and DF-49, respectively; see Hilker et al. 2010a). At SOA, $\varepsilon$ related closely to chlorophyll content estimated from the index-based approaches as well as PROSAIL. 


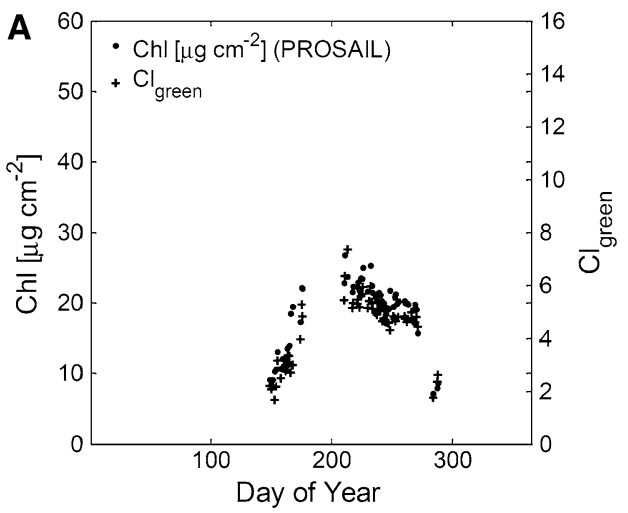

Fig. 3 Seasonal variation of PROSAIL and $\mathrm{Chl}_{\text {green }}$ derived pigment content of chlorophyll for the SOA a and DF-49 site. The $x$-axis shows the day of year (DOY), the $y$-axes represent the total chlorophyll $-a$ and $-b$ contents from PROSAIL and $\mathrm{CI}_{\text {green }}$.

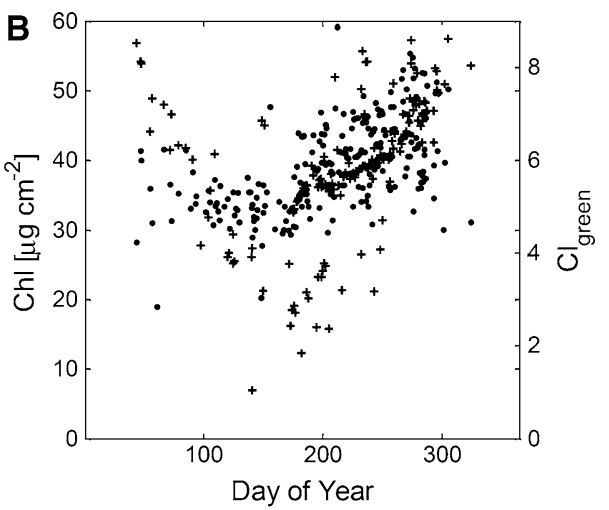

Relationship between PROSAIL-derived estimates and index-based methods were $r^{2}=0.90$ for the SOA site (a) and $r^{2}=0.69$ for the DF-49 site $(\mathbf{b})$, respectively $(P<0.01)$
Fig. 4 Seasonal variation of PROSAIL and $\mathrm{CRI}_{\text {green }}$ derived carotenoid content for the SOA (a) and DF-49 (b) sites. The coefficient of determination between the canopy reflectance model and the index based method was $r^{2}=0.91$ (SOA), $r^{2}=0.66($ DF-49); $P<0.01$
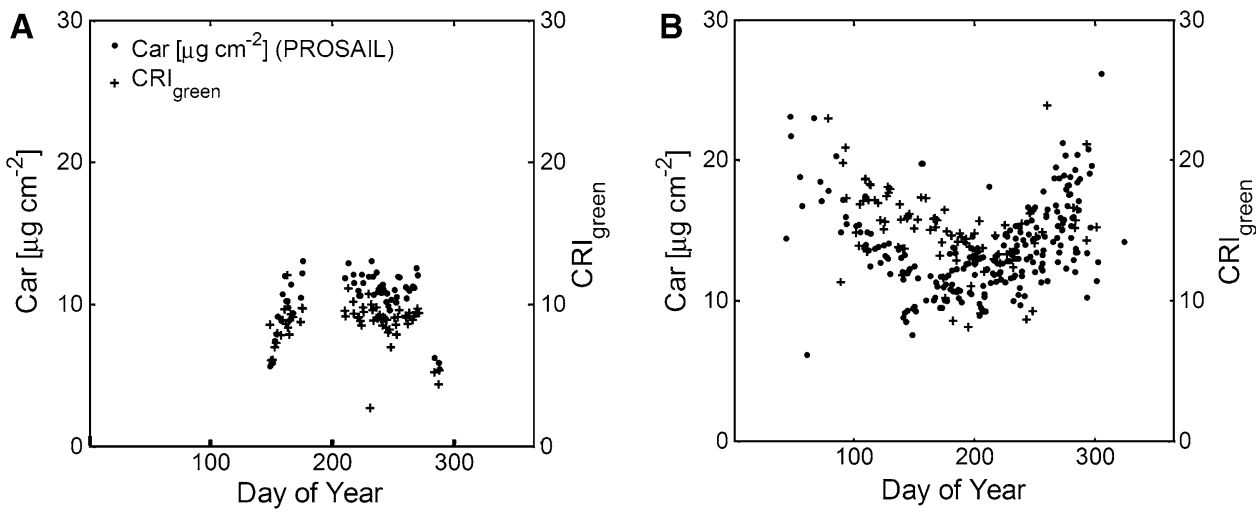

Fig. 5 Seasonal variation of the ratio of carotenoids to chlorophyll, also known as pigment pool size, at SOA (a) and DF-49 (b) showing estimates from PROSAIL as well as the semi-analytical approach of Gitelson et al. $(1999,2003)$

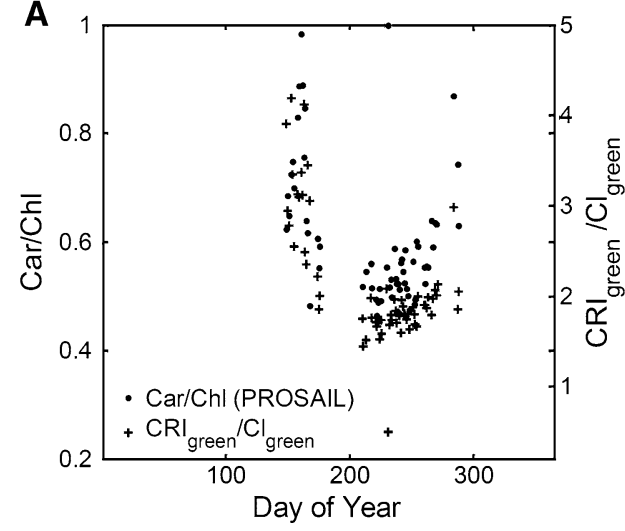

Pigment content and vegetation growth

Net ecosystem production (NEP) followed a seasonal pattern at both sites. Figure $7 \mathrm{a}$ and $\mathrm{b}$ present NEP as estimated from eddy covariance measurements (daytime averages) at the SOA and DF-49 site during the observation period. Growth was limited to only about 150 days a year at the SOA site, while the DF-49 site showed growth year-round as a result of the very temperate climatic conditions. On average, NEP at the SOA site ranged between 0 and $22 \mu \mathrm{mol} \mathrm{m}{ }^{-2} \mathrm{~s}^{-1}$, whereas at DF-49, maximum daily NEP rates were around $27 \mu \mathrm{mol} \mathrm{m} \mathrm{m}^{-2} \mathrm{~s}^{-1}$. The production maximum was reached at the SOA site at around DOY 218; at DF-49, productivity peaked at around DOY 190. Figure 7c and d show the relationship between NEP and canopy pigment contents derived using the analytical and semi-analytical approaches. A strong relationship was found between NEP and the chlorophyll pigments at SOA 
Fig. 6 Seasonal trends in photosynthetic light-use efficiency $(\varepsilon)$ and the photochemical reflectance index (PRI) at SOA (a) and DF-49 (b) PRI was estimated from halfhourly, multi-angular observations using methods of Hilker et al. (2008)

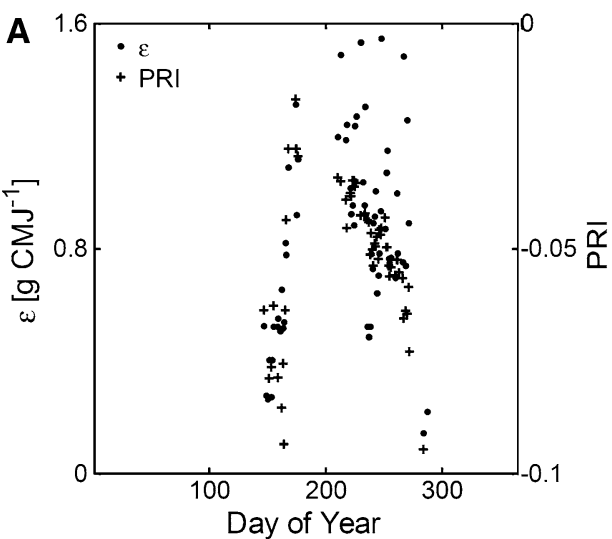

with changes in the chlorophyll content explaining about $70 \%$ of the variability in NEP (Fig. 7c). In contrast, no significant correlation was found between NEP and chlorophyll contents at the DF-49 site using either approach (Fig. 7d). At both sites, car/chl was significantly, but not strongly related to $f_{\text {par }}\left(r^{2}=0.36, r^{2}=0.42, P<0.05\right.$, for SOA and DF-49, respectively). This does, however, exempt the leaf-out period at SOA (DOY $<180$ excluded). During leaf-out car/chl was correlated to the growing degree days, defined as the average of the daily maximum and minimum temperatures compared to a base temperature of $10^{\circ} \mathrm{C} \quad\left(r^{2}=0.81 ; P<0.05\right)$. Figure 8 shows observations of car/chl for the first 2 weeks of the season at SOA (up to 1 June).

\section{Discussion and conclusion}

This study investigated seasonal trends and variations in leaf pigment contents at a deciduous and a coniferous forest in central and coastal Canada. The chlorophyll and carotenoid content observed from spectral observations showed similar seasonal trends as the phenological observations made by the webcam, especially in case of the SOA site (Fig. 2a). This result confirms the findings of previous studies (Richardson et al. 2007, 2009). However, minimum and maximum values of the phenological assessment (Fig. 2a) lagged by about 20 days compared to those estimated for chlorophyll and carotenoid contents. A likely reason for this lag is that pigment content was obtained from multi-angular data, while phenological assessment was acquired from a single, off-nadir angle (Hilker et al. 2010a). In particular, the understorey, which emerges before the aspen overstorey (Barr et al. 2007) would likely be more visible from smaller zenith angles, thus providing more prominent features in the 2G_RB $\mathrm{B}_{\mathrm{i}}$ value early in the year. Multiangular assessment of canopy phenology would be possible from AMSPEC II data and could potentially provide valuable information. This will be investigated in a separate study.

The pigment levels reported in this study agree well with the results found in previous work (Zhang et al. 2008) investigating leaf pigment content in aspen in southern Ontario using the PROSAIL model. A comparison between field methods and remote sensing data showed leaf chlorophyll contents between 27.2 and $43.4 \mu \mathrm{g} \mathrm{cm}^{-2}$ (Zhang et al. 2007). For Douglas fir canopies, chlorophyll contents between 20 and $70 \mu \mathrm{g} \mathrm{cm}^{-2}$ have been reported (Yoder and Waring 1994). Sims and Gamon (2002) investigated ratios of carotenoid to chlorophyll across a wide range of species. Values ranged between 0.3 and 0.8 with the vast majority of observations being $<0.6$ across a wide range of species including Populus. This result corresponds well to the data presented for SOA and DF49 (Fig. 5).

Canopy reflectance models such as PROSAIL yield values of pigment contents with units of $\mu \mathrm{g} \mathrm{cm}^{-2}$, which is determined by the product of the average leaf pigment content times the total amount of leaf area per unit ground surface. As a result, the trends shown in Figs. 3, 4, 5 and 7 are, to a large extent, due to actual changes in canopy leaf area rather than changes in leaf pigment concentration (Zhang et al. 2006). This corresponds well with the much stronger seasonal trend observed at the SOA site in comparison to the temperate evergreen forest at DF-49. The semi-analytical approach for estimating chlorophyll and carotenoids applied in here was calibrated and validated against PROSAIL (Gitelson et al. 2005). The good agreement between these two methods demonstrates that the multi-angular observations were successfully used to minimize structural and directional effects of the spectral observations.

The seasonal variation in chlorophyll and carotenoid content shown in Figs. 3 and 4 reflects the large physiological, structural and climatic differences found at the aspen and the Douglas-fir site. While the evergreen DF-49 stand is located in the temperate climate of coastal British Columbia, which allows tree growth throughout the year 
Fig. 7 Comparison between EC-measured stand growth and AMSPEC estimated chlorophyll content. a, b Seasonal variation in NEP as measured from eddy covariance data at SOA and DF49 , respectively. c,

d Relationship between NEP and the chlorophyll content as estimated from PROSAIL and index-based approaches (c SOA; d DF-49)
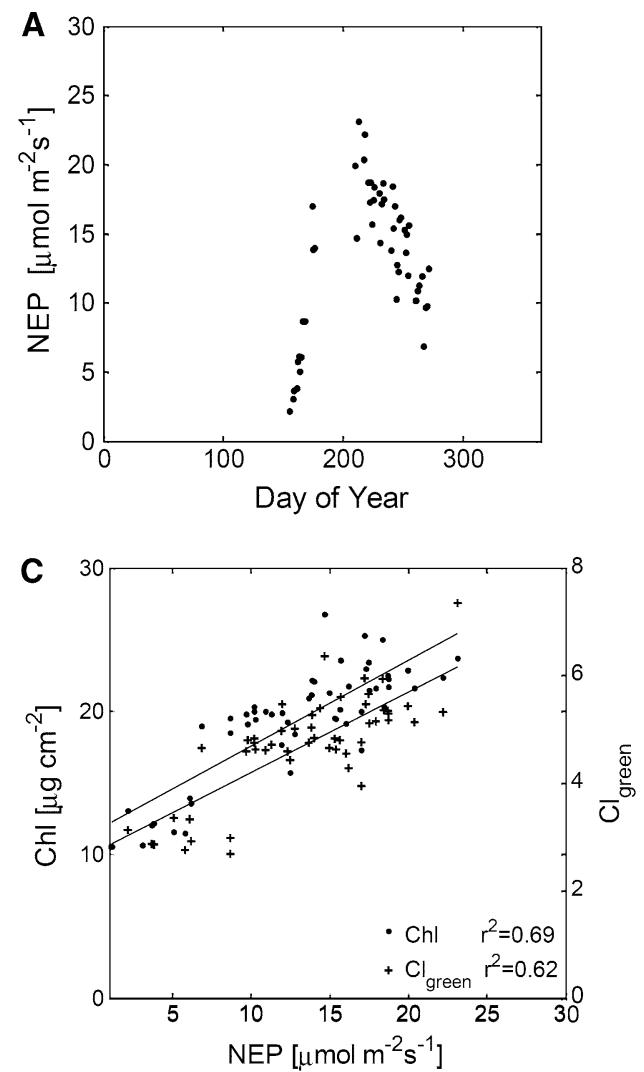

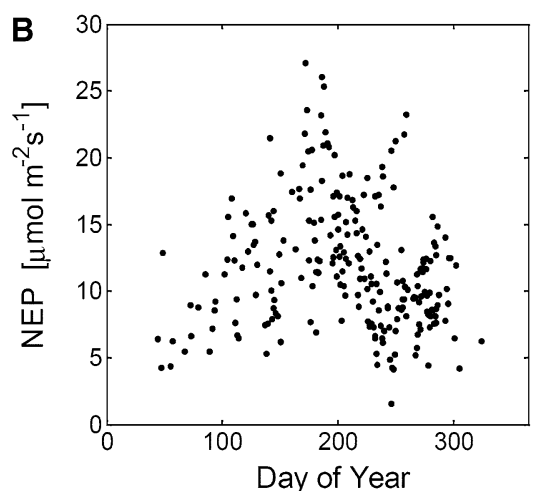

D

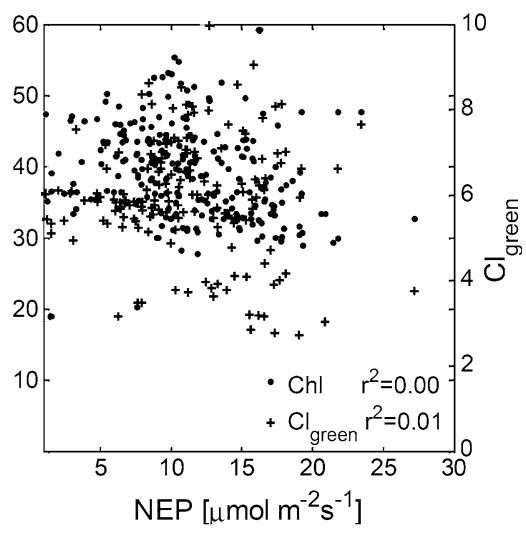

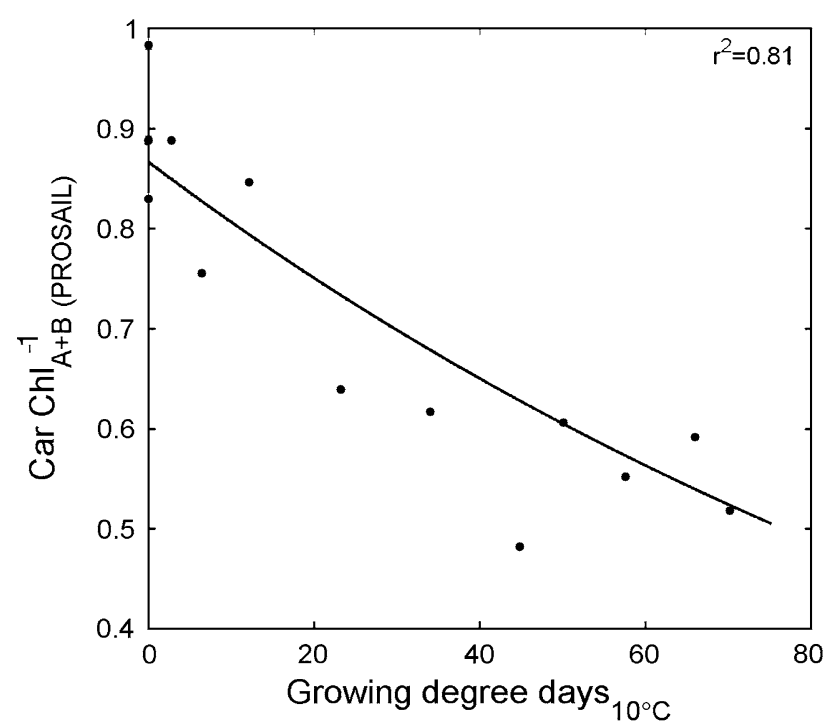

Fig. 8 Relationship between growing degree days (computed to the base of $10^{\circ} \mathrm{C}$ ) and car/chl at SOA $(A)$ up to 1 June

(Morgenstern et al. 2004), the deciduous stand is subject to distinct seasonality and the growing season is determined by spring green-up and leaf senescence in fall (Hilker et al. 2010a). The much more distinct changes in chlorophyll and carotenoid contents at SOA compared to DF-49 (Figs. 3 and 4) are most likely a result of the changes in leaf mass rather than the pigment concentration within the leaf
(Zhang et al. 2006). The higher amount of carotenoids in comparison to chlorophylls in aspen at the beginning of the vegetation season (Fig. 5a) is expected, as foliage requires protection from photo-oxidative damage, particularly while the photosynthetic apparatus is not completely matured (Lewandowska and Jarvis 1977). A possible way to investigate this further would be by fitting a light response curve to eddy-flux measurements in order to model the quantum-use efficiency and the photosynthetic potential. One such model that could potentially be used is the light response curve reviewed by Ruimy et al. (1995).

The weak seasonal signal in chlorophyll content observed at DF-49 is indicative of the year-round capacity of this stand to photosynthesize, while the greater need to downregulate photosynthesis during the winter months (potential for frost stress) corresponds well with the elevated carotenoid contents during this time (Figs. 4b and 5b) (Lewandowska and Jarvis 1977). This agrees well also with the results of the phenological assessment shown in Fig. 2. The potential of the Douglas-fir stand to photosynthesize year-round is also reflected in the daily estimates of the photosynthetic efficiency (Fig. 6b), which show no seasonal trend throughout the year. The relationship between PRI and $\varepsilon$ at DF-49 and SOA is discussed in detail elsewhere (Hilker et al. 2008, 2010a). However, numerous studies (Filella et al. 2009; Sims and Gamon 2002; Stylinski et al. 2002) have demonstrated that PRI can be correlated to 
the car/chl ratio, which could potentially have a confounding effect on measurements of $\varepsilon$ using PRI. While this issue requires further investigation, our results indicate that part of this relationship could be due to a photosynthetic down-regulation during leave-out and leaf senescence, as EC-measured $\varepsilon$ also relates well to changes in pigment pool size at the SOA site (Figs. 5a and 6a).

The PROSAIL derived estimates of chlorophyll and carotenoid pigments correspond well with the semi-analytical approaches of Gitelson et al. (2003) and (2006) (Figs. 3, 4 and 5). The indices, originally developed for crops (Gitelson et al. 2005, 2006; Merzlyak et al. 2003), showed a good agreement at both sites, but in particular for SOA, suggesting a broader applicability also across forested stands using this multi-angular technique. As often the case with studies investigating physiological properties at canopy scales or over longer time spans, the validation of the remote sensing data is problematic, as a direct measurement of pigment contents in situ and at high temporal frequencies throughout the year is impractical. As a result, validation of the data presented in this paper can only be obtained indirectly through comparison to other optical methods and with physiological data obtained for instance from eddy-covariance methods. We recognize this limitation, however, the good correspondence between the spectrally acquired results by PROSAIL and the semianalytical approaches, results presented in Figs. 3, 4, 5 and 6 and the close correspondence to NEP, $\varepsilon$ and soil temperature, does indicate that the seasonal changes in pigment contents have been well described from multi-angular observations by both PROSAIL and empirical methods.

One of the most notable differences between the aspen and the Douglas-fir stand is the way in which NEP is controlled by leaf pigments. At the SOA site, changes in NEP can largely be explained through changes chlorophyll pigment content (driven mainly by changes in leaf area), while there was no correspondence between PROSAIL estimated leaf pigments and EC-measured NEP at the DF49 site. The effect shown in Fig. 7c is also confirmed by previous results found in crops (Gitelson et al. 2006). The strong dependence of NEP on pigment content supports the hypothesis that changes in chlorophyll content (in $\mu \mathrm{g} \mathrm{cm}^{-2}$ ) at SOA are mostly driven by changes in leaf area during green-up and senescence phase, which in turn drives the amount of canopy-absorbed photosynthetically active radiation (APAR). The lack of dependence of NEP rates on chlorophyll contents at the DF-49 site is possibly due to the expected little seasonal variation in leaf area (Fig. 3b).

This study has shown the potential of multi-angular remote sensing to determine biochemical constituents of leaves in a rapid and non-invasive fashion. To the best of our knowledge this is the first example of continuous standlevel observations of canopy pigment content, which we presented as daily averaged values. Tower-based micrometeorological and eddy covariance measurements of $\mathrm{CO}_{2}$ exchange between the canopy surface and its surrounding air column have greatly improved our understanding of the fluxes of carbon, water and energy throughout the least 20 years (Baldocchi 2003). The integration of such observations with continuous, stand-level and multi-angular remote sensing, such as demonstrated in this study, will open new possibilities for comprehensive analysis of plant physiological behavior from the biochemistry of leaves to the carbon and water uptake of plants.

At the stand and landscape level, multi-angular, spectral observations can play a key role in decomposing and explaining stand-level fluxes and could lead to a more integrated and comprehensive understanding of plant physiological behavior. This understanding will not only help improving future models of biogeochemical cycles at landscape and global scales, but it may also lead to new possibilities for observing plant biochemistry in a globally continuous fashion from space (Hilker et al. 2010a, b). As a result, findings of stand level multi-angular studies, such as presented in this paper, can help to inform on the requirements of future satellite missions designed to describe canopy biochemistry and physiological processes of terrestrial vegetation in a spatially continuous manner and at regular intervals. Instrumentations such as AMSPEC II can also be a highly valuable addition to tower-based scientific networks such as Fluxnet (Baldocchi et al. 2001) or other integrated approaches such as National Ecological Observatory Network (NEON) (Lowman et al. 2009).

Acknowledgments Thank you to Zoran Nesic, Dominic Lessard, Andrew Hum and Rick Ketler from UBC Faculty of Land and Food Systems (LFS) for their assistance in technical design, installation, and maintenance of AMSPEC II. This research is partially funded by the Canadian Carbon Program, the Natural Sciences and Engineering Research Council of Canada (NSERC) and BIOCAP, and an NSERCAccelerator grant to Dr. Coops.

\section{References}

Baldocchi DD (2003) Assessing the eddy covariance technique for evaluating carbon dioxide exchange rates of ecosystems: past, present and future. Glob Change Biol 9:479-492

Baldocchi D et al (2001) Fluxnet: a new tool to study the temporal and spatial variability of ecosystem-scale carbon dioxide, water vapor, and energy flux densities. Bull Am Meteorol Soc 82:2415-2434

Baret F, Jacquemoud S, Guyot G, Leprieur C (1992) Modeled analysis of the biophysical nature of spectral shirts and comparison with information content of broad bands. Remote Sens Environ 41:133-142

Barr AG, Black TA, Hogg EH, Kljun N, Morgenstern K, Nesic Z (2004) Inter-annual variability in the leaf area index of a boreal aspen-hazelnut forest in relation to net ecosystem production. Agric For Meteorol 126:237-255 
Barr AG et al (2007) Climatic controls on the carbon and water balances of a boreal aspen forest, 1994-2003. Glob Change Biol 13:561-576

Bicheron P, Leroy M (1999) A method of biophysical parameter retrieval at global scale by inversion of a vegetation reflectance model. Remote Sens Environ 67:251-266

Chen J, Leblanc S (1997) A four-scale bidirectional reflectance model based on canopy architecture. IEEE Trans Geosci Remote Sens 35:1316-1337

Chen JM, Liu J, Leblanc SG, Lacaze R, Roujean JL (2003) Multiangular optical remote sensing for assessing vegetation structure and carbon absorption. Remote Sens Environ 84:516-525

Chen JM, Govind A, Sonnentag O, Zhang YQ, Barr A, Amiro BD (2006) Leaf area index measurements at Fluxnet-Canada forest sites. Agric For Meteorol 140:257-268

Coleman TF, Li YY (1996) An interior trust region approach for nonlinear minimization subject to bounds. SIAM J Optim $6: 418-445$

Coleman TF, Liu JG, Yuan W (2002) A new trust-region algorithm for equality constrained optimization. Comput Optim Appl 21:177-199

Damm A et al (2010) Remote sensing of sun-induced fluorescence to improve modeling of diurnal courses of gross primary production (GPP). Glob Change Biol 16:171-186

Field C, Chapin F III, Matson P, Mooney H (1992) Responses of terrestrial ecosystems to the changing atmosphere: a resourcebased approach. Annu Rev Ecol Syst 23:201-235

Filella I, Porcar-Castell A, Munne-Bosch S, Back J, Garbulsky MF, Penuelas J (2009) PRI assessment of long-term changes in carotenoids/chlorophyll ratio and short-term changes in deepoxidation state of the xanthophyll cycle. Int J Remote Sens 30:4443-4455

Gamon JA, Penuelas J, Field CB (1992) A narrow-waveband spectral index that tracks diurnal changes in photosynthetic efficiency. Remote Sens Environ 41:35-44

Gamon JA, Filella I, Penuelas J (eds) (1993) The dynamic 531-nanometer reflectance signal: a survey of twenty angiosperm species. American Society of Plant Physiologists, Rockville

Gao W, Schaaf CB (2003) Detecting vegetation structure using a kernel-based BRDF model. Remote Sens Environ 86:198-205

Gitelson AA, Buschmann C, Lichtenthaler HK (1999) The chlorophyll fluorescence ratio F-735/F-700 as an accurate measure of the chlorophyll content in plants. Remote Sens Environ 69:296-302

Gitelson AA, Gritz Y, Merzlyak MN (2003) Relationships between leaf chlorophyll content and spectral reflectance and algorithms for non-destructive chlorophyll assessment in higher plant leaves. J Plant Physiol 160:271-282

Gitelson AA, Vina A, Ciganda V, Rundquist DC, Arkebauer TJ (2005) Remote estimation of canopy chlorophyll content in crops. Geophys Res Lett 32

Gitelson AA et al (2006) Relationship between gross primary production and chlorophyll content in crops: implications for the synoptic monitoring of vegetation productivity. J Geophys Res Atmos 111:1-13

Goel NS, Strebel DE (1983) Inverstion of vegetation canopy reflectance models for estimating agronomic variables. 1. Problem definition and initial results using the suits model. Remote Sens Environ 13:487-507

Goel NS, Thompson RL (1984) Inverstion of vegetation canopy reflectance models for estimating agronomic variables. 4. Total inversion of the SAIL model. Remote Sens Environ 15:237-253

Hall FG, Townshend JR, Engman ET (1995) Status of remote-sensing algorithms for estimation of land-surface state parameters. Remote Sens Environ 51:138-156
Hall FG et al (2008) Multi-angle remote sensing of forest light use efficiency by observing PRI variation with canopy shadow fraction. Remote Sen Environ 112:3201-3211

Hilker T, Coops NC, Nesic Z, Wulder MA, Black AT (2007) Instrumentation and approach for unattended year round towerbased measurements of spectral reflectance. Comput Electron Agric 56:72-84

Hilker T et al (2008) Separating physiologically and directionally induced changes in PRI using BRDF models. Remote Sens Environ 112:2777-2788

Hilker $\mathrm{T}$ et al (2010a) Remote sensing of photosynthetic light-use efficiency across two forested biomes: spatial scaling. Remote Sens Environ 114:2863-2874

Hilker T, Nesic Z, Coops NC, Lessard D (2010b) A new, automated, multi-angular radiometer instrument for tower-based observation of canopy reflectance (AMSPEC II). Instrum Sci Technol 38:319

Humphreys ER et al (2006) Carbon dioxide fluxes in coastal douglasfir stands at different stages of development after clearcut harvesting. Agric For Meteorol 140:6-22

Jacquemoud S, Bacour C, Poilve H, Frangi JP (2000) Comparison of four radiative transfer models to simulate plant canopies reflectance: direct and inverse mode. Remote Sens Environ 74:471-481

Jacquemoud S et al (2009) PROSPECT plus SAIL models: a review of use for vegetation characterization. Remote Sens Environ 113:S56-S66

Jassal RS et al (2007) Components of ecosystem respiration and an estimate of net primary productivity of an intermediate-aged douglas-fir stand. Agric For Meteorol 144:44-57

Kempeneers P et al (2008) Model inversion for chlorophyll estimation in open canopies from hyperspectral imagery. Int J Remote Sens 29:5093-5111

Kuusk A (1998) Monitoring of vegetation parameters on large areas by the inversion of a canopy reflectance model. Int $\mathrm{J}$ Remote Sens 19:2893-2905

Lewandowska M, Jarvis PG (1977) Changes in chlorophyll and carotenoid content, specific leaf area and dry-weight fraction in sitka spruce, in response to shading and season. New Phytol 79:247-256

Li XW, Strahler AH (1985) Geometric-optical modeling of a conifer forest canopy. IEEE Trans Geosci Remote Sens 23:705-721

Los SO, North PRJ, Grey WMF, Barnsley MJ (2005) A method to convert AVHRR normalized difference vegetation index time series to a standard viewing and illumination geometry. Remote Sens Environ 99:400-411

Lowman M, D’Avanzo C, Brewer C (2009) A national ecological network for research and education. Science 323:1172-1173

Matsubara S et al (2008) Lutein epoxide cycle, light harvesting and photoprotection in species of the tropical tree genus Inga. Plant Cell Environ 31:548-561

Meroni M, Colombo R, Panigada C (2004) Inversion of a radiative transfer model with hyperspectral observations for Lai mapping in poplar plantations. Remote Sens Environ 92:195-206

Merzlyak MN, Gitelson AA, Chivkunova OB, Solovchenko AE, Pogosyan SI (2003) Application of reflectance spectroscopy for analysis of higher plant pigments. Russ J Plant Physiol 50:704-710

Monteith JL (1972) Solar-radiation and productivity in tropical ecosystems. J Appl Ecol 9:747-766

Monteith JL (1977) Climate and efficiency of crop production in Britain. Philos Trans R Soc Lond B 281:277-294

Morgenstern K et al (2004) Sensitivity and uncertainty of the carbon balance of a pacific northwest douglas-fir forest during an El Nino La Nina cycle. Agric For Meteorol 123:201-219 
Myneni R, Hall F, Sellers P, Marshak A (1995) The interpretation of spectral vegetation indexes. IEEE Trans Geosci Remote Sens 33:481-486

Ozanne CMP et al (2003) Biodiversity meets the atmosphere: a global view of forest canopies. Science 301:183-186

Price J (1992) Estimating vegetation amount from visible and near infrared reflectances. Remote Sens Environ 41:29-34

Privette JL, Emery WJ, Schimel DS (1996) Inversion of a vegetation reflectance model with NOAA AVHRR data. Remote Sens Environ 58:187-200

Richardson AD, Jenkins JP, Braswell BH, Hollinger DY, Ollinger SV, Smith ML (2007) Use of digital webcam images to track spring green-up in a deciduous broadleaf forest. Oecologia 152:323-334

Richardson AD, Hollinger DY, Dail DB, Lee JT, Munger JW, O'Keefe J (2009) Influence of spring phenology on seasonal and annual carbon balance in two contrasting New England forests. Tree Physiol 29:321-331

Ross JK (1981) The radiation regime and architecture of plant stands. Junk, The Hague

Roujean JL, Leroy M, Deschamps PY (1992) A bidirectional reflectance model of the earths surface for the correction of remote-sensing data. J Geophys Res Atmos 97:20455-20468

Ruimy A, Jarvis PG, Baldocchi DD, Saugier B (1995) $\mathrm{CO}_{2}$ flux over plant canopies and solar radiation: a review. Adv Ecol Res 26:1-63

Sellers P et al (1995) The Boreal Ecosystem-Atmosphere Study (BOREAS): an overview and early results from the 1994 field year. Bull Am Meteorol Soc 76:1549-1577

Sims DA, Gamon JA (2002) Relationships between leaf pigment content and spectral reflectance across a wide range of species, leaf structures and developmental stages. Remote Sens Environ 81:337-354

Stylinski CD, Gamon JA, Oechel WC (2002) Seasonal patterns of reflectance indices, carotenoid pigments and photosynthesis of evergreen chaparral species. Oecologia 131:366-374

Suits GH (1972) The calculation of the directional reflectance of a vegetative canopy. Remote Sens Environ 2:117-125

Tanja S et al (2003) Air temperature triggers the recovery of evergreen boreal forest photosynthesis in spring. Glob Change Biol 9:1410-1426
Ustin SL et al (2009) Retrieval of foliar information about plant pigment systems from high resolution spectroscopy. Remote Sens Environ 113:S67-S77

Verhoef W (1984) Light scattering by leaf layers with application to canopy reflectance modeling: the SAIL model. Remote Sens Environ 16:125-141

Verrelst J, Schaepman ME, Koetz B, Kneubuhler M (2008) Angular sensitivity analysis of vegetation indices derived from CHRIS/ PROBA data. Remote Sens Environ 112:2341-2353

Verstraete MM, Pinty B (2001) Introduction to special section: modeling, measurement, and exploitation of anisotropy in the radiation field. J Geophys Res Atmos 106:11903-11907

Verstraete MM, Pinty B, Myneni RB (1996) Potential and limitations of information extraction on the terrestrial biosphere from satellite remote sensing. Remote Sens Environ 58:201-214

Wanner W, Li X, Strahler A (1995) On the derivation of kernels for kernel-driven models of bidirectional reflectance. J Geophys Res 100:21077-21089

Weiss M, Baret F, Myneni RB, Pragnere A, Knyazikhin Y (2000) Investigation of a model inversion technique to estimate canopy biophysical variables from spectral and directional reflectance data. Agronomie 20:3-22

Yoder B, Waring R (1994) The normalized difference vegetation index of small douglas-fir canopies with varying chlorophyll concentrations. Remote Sens Environ 49:81-91

Zarco-Tejada PJ, Miller JR, Morales A, Berjon A, Aguera J (2004) Hyperspectral indices and model simulation for chlorophyll estimation in open-canopy tree crops. Remote Sens Environ 90:463-476

Zhang QY et al (2006) Characterization of seasonal variation of forest canopy in a temperate deciduous broadleaf forest, using daily MODIS data. Remote Sens Environ 105:189-203

Zhang YQ, Chen JM, Thomas SC (2007) Retrieving seasonal variation in chlorophyll content of overstory and understory sugar maple leaves from leaf-level hyperspectral data. Can J Remote Sens 33:406-415

Zhang YQ, Chen JM, Miller JR, Noland TL (2008) Leaf chlorophyll content retrieval from airborne hyperspectral remote sensing imagery. Remote Sens Environ 112:3234-3247 